\title{
A COLUNA SEDIMENTAR COMO RESERVATÓRIO E FONTE DE NUTRIENTES EM ENSEADAS ESTUARINAS.
}

\author{
Maria da Graça Zepka BAUMGARTEN \\ Luis Felipe Hax NIENCHESKI
}

\begin{abstract}
RESUMO
O estuário da Lagoa dos Patos possui várias enseadas marginais semi-fechadas e com alta produtividade, conhecidas como "Sacos". As águas das margens do Saco da Mangueira são receptoras da descarga de efluentes insuficientemente tratados, oficiais e clandestinos, oriundos da cidade do Rio Grande e do Distrito Industrial, que se localizam nas margens dessa enseada. O Saco do Justino não recebe aportes de nutrientes de origem antrópica. Ambas enseadas são criadouros de muitas espécies de peixes e crustáceos de valor comercial. Mensalmente, de 1994 a 1995, foram determinadas as concentrações de amônio, fosfato, salinidade e Eh da coluna d'água e da água intersticial da coluna sedimentar de até cerca de $40 \mathrm{~cm}$ de profundidade nessas enseadas. Os resultados evidenciaram que o Saco da Mangueira apresentou eutrofização duas vezes maior do que o do Saco do Justino. Em ambas enseadas os gradientes das concentrações de nutrientes aumentaram em direção ao fundo da coluna sedimentar, com concentração de amônio em torno de 10 vezes maior na água intersticial da interface da coluna sedimentar do que na coluna d'água, sendo que para o fosfato esse aumento foi de 2 vezes. Portanto, nas enseadas não poluídas a água intersticial é uma natural e importante fonte de amônio e de fosfato para a coluna d'água, através de processos de advecção e/ou difusão molecular. Isso foi favorecido pela penetração da água do mar na coluna sedimentar, com conseqüente aumento nos intercâmbios com a coluna d'água. A penetração da água do mar perturbou a estabilidade da coluna sedimentar das enseadas e quebrou a estratificação formada entre a condição oxidante das camadas superficiais e a condição redutora das camadas mais profundas, onde estava acumulada a água intersticial rica em nutrientes. Isso foi constatado principalmente no Saco da Mangueira.
\end{abstract}

Palavras chave: água intersticial; nutrientes; Lagoa dos Patos. Estuário.

\section{SEDIMENTS AS A SOURCE AND RESERVOIR OF NUTRIENTS IN ESTUARINE SEMI- ENCLOSED BAYS.}

\section{ABSTRACT}

Patos Lagoon estuary has several shallow and high productivity marginal bays. Saco da Mangueira is a semi-enclosed bay contaminated by the discharge of poorlytreated, official and clandestine household and industrial effluents from Rio Grande City and from District Industrial. Saco do Justino doesn't receive direct input of any anthropogenic nutrients. Both semi-enclosed bays are used as a nursery for many valuable commercial specie of fish and crustacean. Monthly, from 1994 to 1995, ammonium, phosphate, Eh and the salinity of water samples and pore water until a sedimentary column of ca $50 \mathrm{~cm}$ were determined. Saco da Mangueira presents an euthrophication level twice higher as that one presented by Saco do Justino. In both bays, the nutrients increased towards the bottom, with a gradient about 10, between the ammonium of the water column and the pore water of the interface. The phosphate gradient was about 2, showing that the natural and the main source of ammonium and phosphate towards water column of the marginal bays is the pore water, through advection and/or molecular diffusion processes. The penetration of the seawater in the sedimentary column increased the exchange with the water column. The seawater disturbed the stability of the sedimentary column and breached the stratification formed between the oxidant condition of the superficial layers and the reducing condition of the deepest layers, where highly contaminated interstitial water accumulated, mainly in the Saco da Mangueira.

Keywords: intersticial water, nutrients, Lagoa dos Patos, estuary. 


\section{INTRODUÇÃO}

Através de vários processos biogeoquímicos, compostos nitrogenados e fosfatados são reciclados na coluna sedimentar de ambientes aquáticos. A água intersticial é uma fonte de íons formados na coluna sedimentar, funcionando como um vetor destes para a coluna da água. Isso pode alterar a qualidade da água sobrejacente, através de fluxos difusivos e advectivos.

Isso ocorre principalmente nas enseadas estuarinas rasas, onde o suprimento de matéria orgânica para a coluna sedimentar normalmente é intenso, fazendo com que a maior parte da remineralização dessa matéria ocorra na interface deposicional e ao longo da coluna sedimentar. Nas enseadas a ação do vento é mais intensa, em função da pouca profundidade. Isso favorece o aumento da hidrodinâmica e a turbulência da água, ressuspendendo os sedimentos superficiais e intensificando os intercâmbios químicos entre a coluna d'água e a coluna sedimentar. A conseqüência é a ativação dos processos de reciclagens e regenerações bênticas de compostos nitrogenados e fosfatados constituintes da matéria orgânica depositada na coluna sedimentar e muito importantes para a produtividade primária das áreas rasas (KENNISH, 1994; BREPHOL, 2001; ZARZUR, 2001).

A entrada da água marinha nas enseadas estuarinas e atividades biológicas como a bioturbação também atuam na ressuspensão dosa sedimentos superficiais (TENGBERG et al., 2003). À esses processos, soma-se as atividades antrópicas como a navegação e, em áreas rasas, principalmente a pesca artezanal comercial.

Com esse enfoque, o presente artigo se refere às enseadas rasas do estuário da Lagoa dos Patos, no sul do Brasil e complementa aspectos enfocados em estudos prévios. ZARZUR (2001) avaliou a regeneração bêntica de nutrientes através por incubações in situ, de câmaras bentônicas transparentes e opacas., instaladas sobre o fundo de quatro enseadas rasas desse estuário, Constatou variação espacial dos fluxos difusivos e concentrações de nutrientes na água intersticial, na dependência dos níveis de aportes antrópicos.para cada enseada estudada, evidenciando a necessidade de ser conhecida a variação temporal da reserva de nutrientes da coluna sedimentar destas enseadas.

NIENCHESKI \& JAHNKE (2002) estudaram a remineralização bêntica de nutrientes na interface sedimento-coluna d'água desse estuário também se baseando nas incubações in situ com câmaras bentônica. Evidenciaram que o sistema bêntico tem importante e decisiva atuação na cadeia trófica local e em menor escala da zona costeira adjacente, uma vez que esse estuário suporta uma alta produção biológica e exporta matéria orgânica e nutrientes em regime de vazante da Lagoa dos Patos, via estuário, para o Oceano Atlântico.

ZARZUR (2007) evidenciou que a compreensão dos processos de intercâmbios entre a água e a coluna sedimentar em termos de potenciais contaminantes da coluna d'água ajuda na predição de impactos e na adoção de práticas para o uso sustentável das enseadas do estuário. Cita a necessidade da inclusão destes processos para os cálculos do balanço de massa e a incorporação em modelos de previsão de impactos ambientais e, assim, torná-los mais realísticos. Além disso, enfatizou que estudos da remineralização da matéria orgânica e diagênese dos nutrientes na coluna sedimentar pode ser considerado uma ótima ferramenta para compreender e avaliar o possível impacto de construções (exemplo pontes e cercados para cultivos) que venham a ser realizadas nas enseadas estuarinas. Também fornecem subsídeos para estratégias de remediação e recuperação desses ambientes rasos, cujos sedimentos estejam e/ou que venham a ser contaminados.

O presente estudo se refere a duas enseadas rasas do estuário da Lagoa dos Patos, denominadas Saco do Justino e Saco da Mangueira, as quais recebem diferentes níveis de aportes antrópicos de nutrientes e matéria orgânica (BAUMGARTEN et al, 2001). O objetivo principal foi identificar ao longo do ano, o papel da água intersticial da interface, superfície e sub-superfície da coluna sedimentar (até cerca de $40 \mathrm{~cm}$ de profundidade) 
BAUMGARTEN; NIENCHESKI. A coluna sedimentar como reservatório e fonte de nutrientes em enseadas estuarinas.

dessas enseadas, como reservatório e fonte de enriquecimento da coluna d'água em amônio e fosfato. Além disso, de forma inédita, se propôs avaliar a influência da entrada da água marinha na coluna sedimentar dessas enseadas, em termos das variações nas concentrações de amônio e fosfato na água intersticial e na coluna d'água.

Esse último objetivo foi motivado pelo fato de que BAUMGARTEN et al. (1995) constataram que a água marinha penetra no estuário da Lagoa dos Patos supersaturada em oxigênio e oligotrófica. Esta entrada é condicionada basicamente pela menor intensidade dos índices pluviométricos e ocorrências de ventos do qradrante sul. Dessa forma, a presença da água marinha no estuário não segue necessariamente um padrão sazonal, mas causa diluições dos efluentes aportados para o estuário.

Portanto, o enfoque apresentado no presente artigo complementa os estudos anteriormente citados sobre a ciclagem de nutrientes entre a água e os sedimentos do estuário, disponibilizando informações inéditas para a região e necessárias para a seqüência e evolução das pesquisas nessa área do conhecimento.

\section{ÁREA DE ESTUDO}

O estuário da Lagoa dos Patos se forma no extremo sul do Rio Grande do Sul e deságua no Oceano Atlântico. Nele existem várias enseadas marginais rasas (média de 1 m de profundidade) conhecidas como "Sacos" (Fig. 1), que são bastante produtivas e são criadouros de várias espécies de peixes e crustáceos comercializáveis (BAUMGARTEN et al., 1995)..

A enseada Saco da Mangueira é margeada de um lado pela cidade do Rio Grande (cerca de 200.000 hab.), em cuja margem estão instaladas duas indústrias de processamento de pescados. Na margem oposta dessa enseada há uma área portuária em crescimento, onde se situa um Distrito Industrial e um Pólo Naval. Em função disso, apesar dessa enseada ser utilizada intensamente para a pesca artesanal, recebe grande carga de efluentes domésticos e industriais, oficiais e clandestinos lançados sem suficiente.tratamento prévio (BAUMGARTEN et al., 2001).

A enseada Saco do Justino não é submetida a aportes diretos de efluentes, pois fica mais distante da cidade. É usado para pesquisas científicas realizadas por equipes da FURG, não sendo liberada para pesca comercial.

O cuidado com a preservação dessas enseadas é reforçado pelo imenso valor ecológico das mesmas no sistema estuarino. Reconhecendo isso, o órgão ambiental estadual (FEPAM), em 1995, concretizou o processo de enquadramento da parte sul do estuário, seguindo as recomendações da Resolução n 20 do CONAMA (1986), atualizadas na Resolução $n^{\circ} 357$ do CONAMA (2005). Nesse processo, o Saco do Justino foi enquadrado como Classe $A$ de águas salobras, onde não são tolerados lançamentos de águas residuárias, domésticas e industriais, lixo e outros resíduos sólidos e substâncias tóxicas, mesmo tratadas. O Saco da Mangueira foi enquadrado como Classe $B$, onde somente podem ser lançados efluentes tratados, desde que não façam com que as concentrações da água ultrapassem os limites recomendados para a respectiva classe de qualidade prevista pelo enquadramento para cada classe de água. 


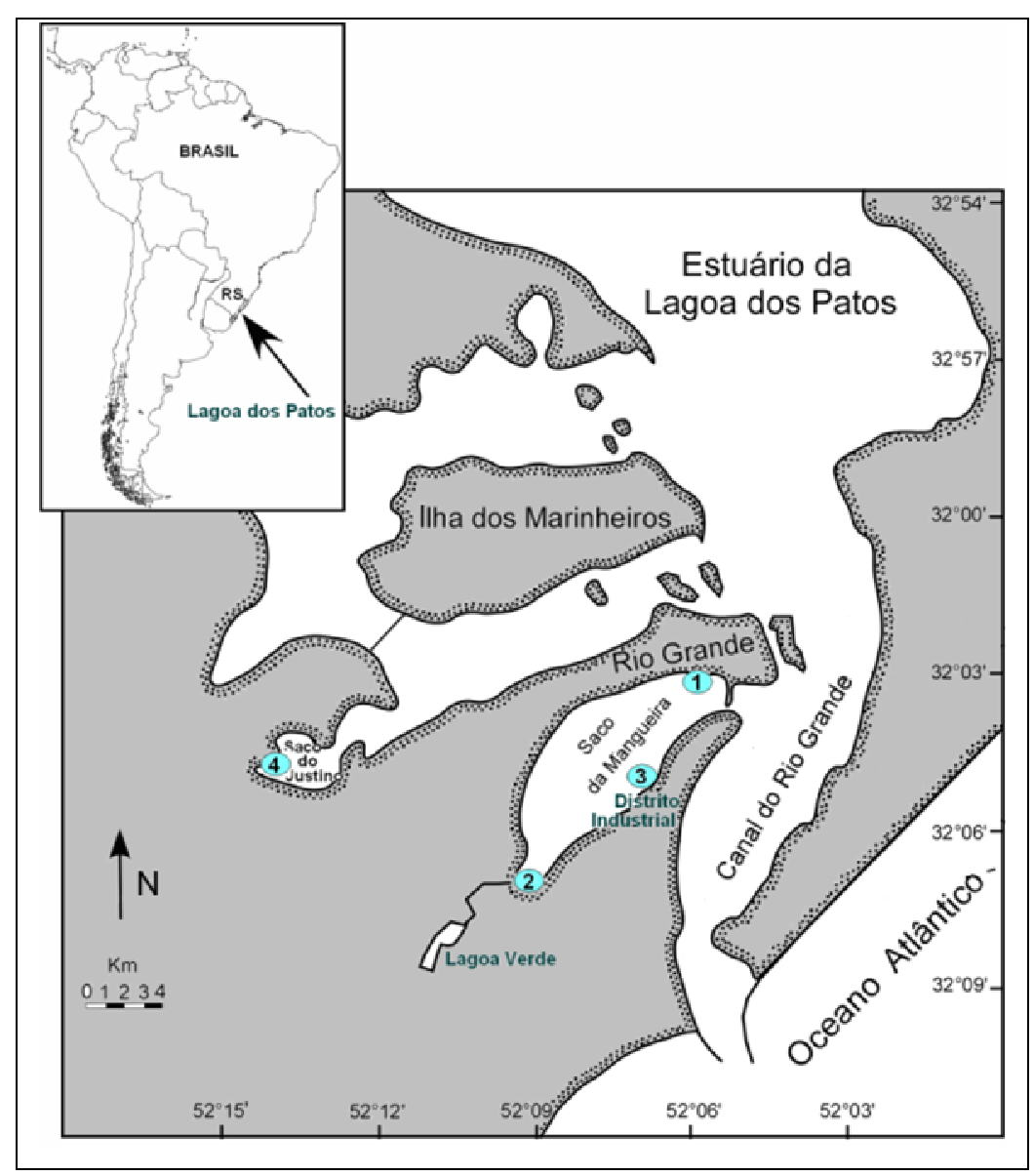

Figura 1 - Estuário da Lagoa dos Patos e identificação dos 4 locais amostrados nas enseadas Saco da Mangueira (locais 1, 2 e 3) e Saco do Justino (local 4) (mapa adaptado de SPENGLER et al., 2007)..

\section{MATERIAL E MÉTODOS}

Tanto no Saco da Mangueira como no Saco do Justino, mensalmente e durante 15 meses (abril/1994 a setembro/1995) foram amostrados quatro locais com profundidade da coluna d'água em torno de 1 a 1,5 metros. As amostragens foram realizadas com 0 uso de um barco para não alterar por pisoteamento a coluna sedimentar analisada,

No Saco da Mangueira foram posicionados três locais (Fig. 1) distribuídos em áreas que recebem aportes de nutrientes de diferentes origens. O local 1 se localizou na margem da cidade do Rio Grande, nas proximidades de efluentes domésticos e industriais clandestinos. O local 2 foi posicionado nas proximidades dos deságües de dois arroios, sendo o local mais distante dos efluentes de origem antrópica que chegam nessa enseada. O local 3 foi posicionado na margem da área onde estão instaladas duas indústrias de fertilizantes.

No Saco do Justino foi amostrado somente o local 4, tendo em vista ser uma enseada menor que o Saco da Mangueira e com características mais naturais.

Para as coletas na superfície e no fundo da coluna d'água foi lançada uma garrafa tipo Van Dorn. Para obter-se água intersticial foi amostrado um testemunho da coluna sedimentar de cada local, para o que foi enterrado a partir do barco, um cano de PVC com $10 \mathrm{~cm}$ de diâmetro e $2 \mathrm{~m}$ de comprimento, o qual penetrou até cerca de $40 \mathrm{~cm}$ de profundidade da coluna sedimentar. Imediatamente depois, o cano foi puxado para o barco. Posteriormente, para a extração da água intersticial esse cano foi levado ao laboratório em uma viatura, onde foi posicionado verticalmente para evitar a mistura e a compactação das camadas sedimentares contidas em seu interior. Além disso, foi transportado com um pouco de água do ambiente no seu topo cobrindo o testemunho 
BAUMGARTEN; NIENCHESKI. A coluna sedimentar como reservatório e fonte de nutrientes em enseadas estuarinas.

sedimentar, para evitar processos oxidativos adicionais na interface sedimentar (BREPHOL, 2000).

No laboratório foi inserido um êmbolo dentro do cano para empurrar o testemunho sedimentar para fora e escorrer a água do topo do cano. À medida que o testemunho saía do cano, ele foi sendo cortado em 11 fatias nas seguintes profundidades: 0,$5 ; 1 ; 2 ; 5 ; 8 ; 13 ; 18 ; 23 ; 28 ; 33$ e $38 \mathrm{~cm}$, visando a obtenção de amostras de água intersticial da interface, superfície e sub-superfície da coluna sedimentar. Assim, esta amostragem estratificada da coluna sedimentar permitiu a obtenção de perfis verticais das concentrações na água intersticial..

Cada fatia de sedimento foi imediatamente inserida em um equipamento extrator de água intersticial descrito em BREPHOL (2000).. Esse extrator é constituído por um sistema de prensa composto por onze placas sobrepostas, feitas de Teflon ${ }^{\circledR}$. Na cavidade central de cada placa foi acomodada uma fatia de sedimentos. As placas preenchidas foram unidas e vedadas. Entre elas foram colocados filtros com porosidade de 0,45 $\mu \mathrm{m}$. O gás nitrogênio foi injetado no sistema todo para fazer pressão em cada fatia sedimentar e extrair a água intersticial. Esse gás manteve o ambiente inerte dentro do extrator, visando não alterar as condições originais de oxi-redução da coluna sedimentar, pois as mesmas se alteram facilmente quando ficam expostas ao ar. Em frascos acoplados em cada uma das placas foi recolhido de cada fatia de sedimentos, cerca de 5 $\mathrm{ml}$ de água intersticial para posterior análise.

Na coluna d'água e na água intersticial de cada profundidade amostrada foram analisados o fosfato e o nitrogênio amoniacal (rotineiramente mencionado como amônio), segundo métodos espectrofotométricos na faixa de luz visível, descritos em BAUMGARTEN et al. (1996). A salinidade foi medida com condutivímetro Yellow Springs modelo 33 SCT. O potencial de óxido-redução (Eh) e o pH da água foram medidos com um potenciômetro com os respectivos eletrodos específicos.

\section{RESULTADOS}

Os locais amostrados não foram diferenciados significativamente pelas variações espaço-temporais da salinidade na coluna d'água e na água intersticial. Para os nutrientes ocorreu o contrário, pois os locais se caracterizaram por diferentes níveis de contaminação (Tabelas 1, 2 e 3), com importantes variações temporais (Figuras 2 e 3)
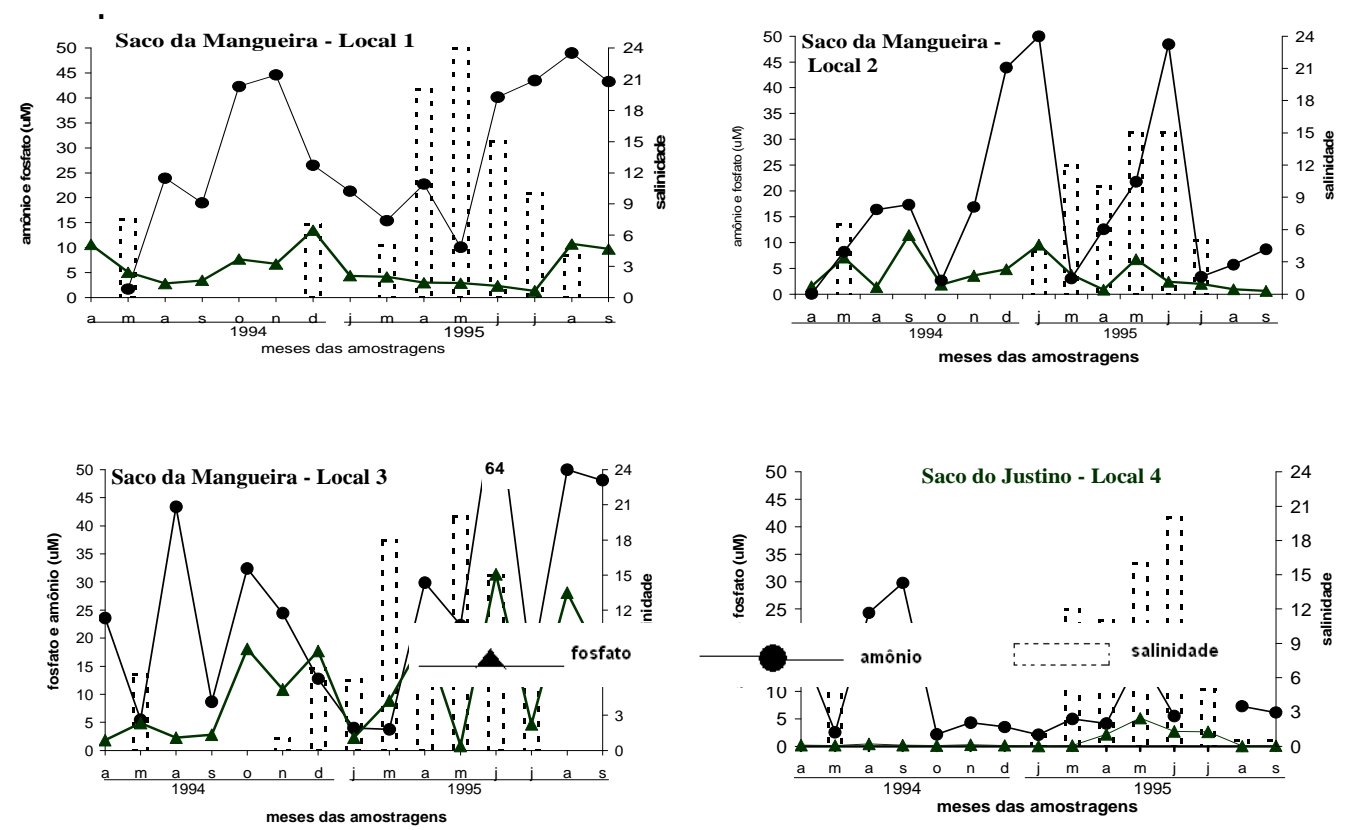

Figura 2 - Concentrações de fosfato $\left(\mu \mathrm{M} \mathrm{P}-\mathrm{PO}_{4}{ }^{3-}\right)$, amônio $\left(\mu \mathrm{M} \mathrm{N}-\mathrm{NH}_{4}{ }^{+}\right)$e salinidade na superfície da coluna d'água do Saco da Mangueira e do Saco do Justino. 

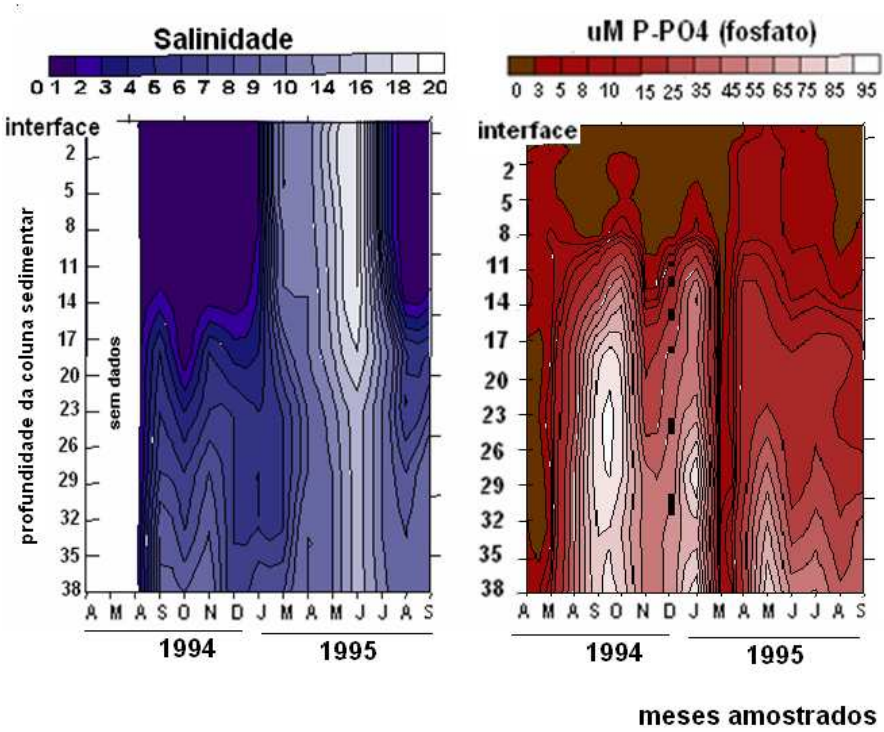

uM N-NH4 (amônio)
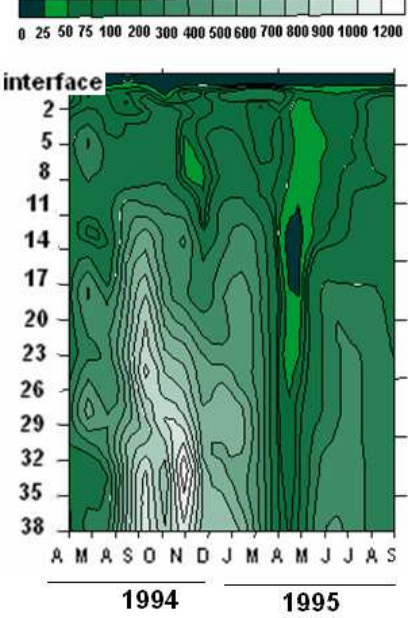

Figura 3 -

Concentrações mensais da salinidade, do fosfato e do amônio na água intersticial do Saco do Justino. Obs.: As cores mais claras em cada gráfico indicam as maiores concentrações e vice-versa.

Tabela 1 - Comparação entre as médias, mínimos e máximos (nos parênteses) da salinidade na coluna da água e na água intersticial da coluna sedimentar no Saco do Justino e no Saco da Mangueira (abril/94 a set/95).

\section{SALINIDADE}

\begin{tabular}{|c|c|c|c|c|}
\hline Profundidade & $\begin{array}{l}\text { Saco do Justino } \\
\text { (área sem } \\
\text { efluentes) } \\
\text { Local } 4\end{array}$ & $\begin{array}{l}\text { Saco da } \\
\text { Mangueira } \\
\text { (efluentes } \\
\text { industriais)l } \\
\text { Local } 3\end{array}$ & $\begin{array}{l}\text { (aportes de } \\
\text { água doce) } \\
\text { Local } \mathbf{2}\end{array}$ & $\begin{array}{l}\text { (efluentes } \\
\text { domésticos) } \\
\text { Local } \mathbf{1}\end{array}$ \\
\hline $\begin{array}{l}\text { Coluna d'água: } \\
\text { Superfície } \\
\text { Fundo } \\
\text { Água } \\
\text { intersticial: }\end{array}$ & $\begin{array}{l}5,4 \\
(0-20) \\
8,3 \\
(0-20)\end{array}$ & $\begin{array}{l}6,5 \\
(0-20) \\
9,6 \\
(0-20)\end{array}$ & $\begin{array}{l}4,7 \\
(0-15) \\
6,8 \\
(0-15)\end{array}$ & $\begin{array}{l}6,6 \\
(0-24) \\
9,6 \\
(0-24)\end{array}$ \\
\hline
\end{tabular}


BAUMGARTEN; NIENCHESKI. A coluna sedimentar como reservatório e fonte de nutrientes em enseadas estuarinas.

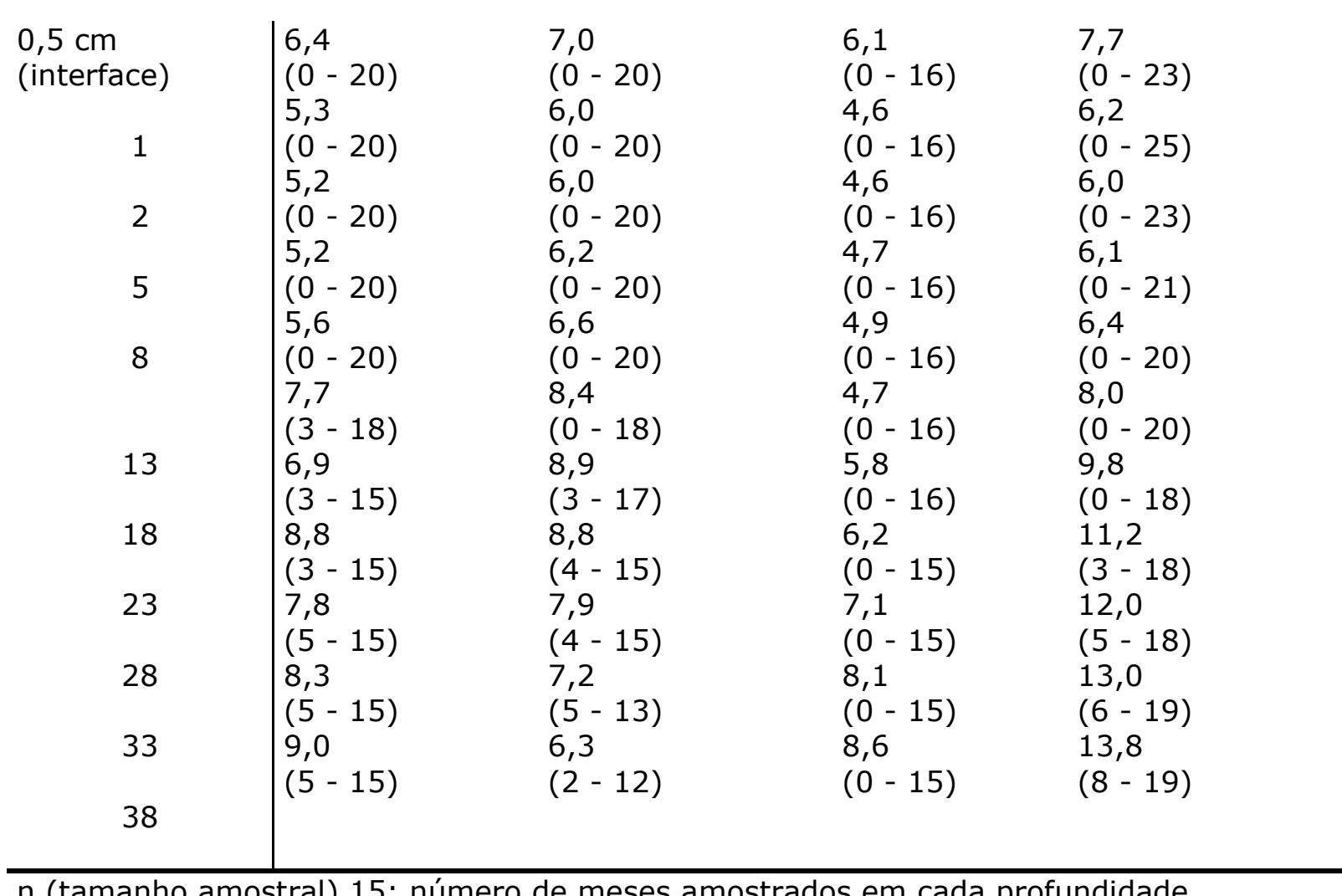

Tabela 2 - Comparação entre as médias, mínimos e máximos (nos parênteses) do fosfato na coluna da água e na água intersticial de cada profundidade da coluna sedimentar no Saco do Justino e no Saco da Mangueira (abril/94 a setembro/95).

\section{A) FOSFATO ( $\left.\mu \mathrm{M} \mathrm{P-PO}{ }_{4}^{3-}\right)$}

\begin{tabular}{|c|c|c|c|c|}
\hline Profundidade & $\begin{array}{l}\frac{\text { Saco do }}{\text { Justino }} \\
\text { (área sem } \\
\text { efluentes) } \\
\text { Local } 4\end{array}$ & $\begin{array}{l}\text { Saco da } \\
\text { Mangueira } \\
\text { (efluentes } \\
\text { Industriais) } \\
\text { Local } 3 \\
\end{array}$ & $\begin{array}{l}\text { (aportes de } \\
\text { água doce) } \\
\text { Local } \mathbf{2}\end{array}$ & $\begin{array}{l}\text { (efluentes } \\
\text { domésticos) } \\
\text { Local } 1\end{array}$ \\
\hline $\begin{array}{l}\text { Coluna d'água: } \\
\text { Superfície } \\
\text { Fundo } \\
\text { Água intersticial: }\end{array}$ & $\begin{array}{l}1,0 \\
(0-5,3) \\
2,4 \\
(0,1-6,9)\end{array}$ & $\begin{array}{l}11,4 \\
(0,8-31,4) \\
14,2 \\
1,0-33,2)\end{array}$ & $\begin{array}{l}1,9 \\
(0,2-5,5) \\
5,5 \\
(0,5-25,9)\end{array}$ & $\begin{array}{l}5,6 \\
(1,3-13,4) \\
7,3 \\
(4,2-11,6)\end{array}$ \\
\hline
\end{tabular}




\begin{tabular}{|c|c|c|c|c|}
\hline $\begin{array}{l}0,5 \mathrm{~cm} \\
\text { (interface) }\end{array}$ & $\mid \begin{array}{l}2,4 \\
(0,1-6,9) \\
2,4\end{array}$ & & $\begin{array}{l}4,4 \\
(2,4-6,6) \\
3,8\end{array}$ & $\begin{array}{l}7,1 \\
(0,6-14,6) \\
5,7\end{array}$ \\
\hline 1 & $(0,1-6,8)$ & 19,7 & $(0,9-12,9)$ & $(1,2-10,6)$ \\
\hline 2 & $\begin{array}{l}2,8 \\
(0,2-6,2)\end{array}$ & $\begin{array}{l}(7,4-27,9) \\
11,4\end{array}$ & $\begin{array}{l}8,8 \\
(0,6-57,2)\end{array}$ & $\begin{array}{l}10,5 \\
(2,8-30,8)\end{array}$ \\
\hline 5 & $\begin{array}{l}2,8 \\
(1,2-8,1) \\
3,8\end{array}$ & $\begin{array}{l}(0,5-21,7) \\
12,5 \\
(2,4-56,6)\end{array}$ & $\begin{array}{l}15,3 \\
(1,5-68,5) \\
18,9\end{array}$ & $\begin{array}{l}12,8 \\
(3,1-68,3) \\
31,2\end{array}$ \\
\hline 8 & $\begin{array}{l}(0,8-60,3) \\
16,7\end{array}$ & $\begin{array}{l}28,7 \\
(1,9-251,5)\end{array}$ & $\begin{array}{l}(2,2-48,8) \\
17,9\end{array}$ & $\begin{array}{l}(7,6-230,5) \\
59,3\end{array}$ \\
\hline 13 & $\begin{array}{l}(1,2-82,7) \\
27,4\end{array}$ & $\begin{array}{l}34,8 \\
(2,6-83,9)\end{array}$ & $\begin{array}{l}(0,9-55,8) \\
28,5\end{array}$ & $\begin{array}{l}(18,8-250,4) \\
67,9\end{array}$ \\
\hline 18 & $\begin{array}{l}(0,3-93,5) \\
30,9\end{array}$ & $\begin{array}{l}68,1 \\
(13,0-133,6)\end{array}$ & $\begin{array}{l}(5,5-54,8) \\
42,9\end{array}$ & $\begin{array}{l}(32,0-140,1) \\
92,4\end{array}$ \\
\hline 23 & $\begin{array}{l}(0,3-93,5) \\
39,9\end{array}$ & $\begin{array}{l}88,9 \\
(12,8-159,3)\end{array}$ & $\begin{array}{l}(6,8-79,2) \\
52,3\end{array}$ & $\begin{array}{l}(57,8-154,7) \\
99,9\end{array}$ \\
\hline 28 & $\begin{array}{l}(1,7-94,8) \\
42,2\end{array}$ & $\begin{array}{l}103,4 \\
(20,3-209,2)\end{array}$ & $\begin{array}{l}(9,3- \\
108,1)\end{array}$ & $\begin{array}{l}(69,6-156,9) \\
101,2\end{array}$ \\
\hline 33 & $\begin{array}{l}(3,0-84,9) \\
48,8\end{array}$ & $\begin{array}{l}111,4 \\
(19,7-150,4)\end{array}$ & $\begin{array}{l}59,0 \\
(11,6-\end{array}$ & $\begin{array}{l}(67,7-192,3) \\
104,0\end{array}$ \\
\hline 38 & $(4,2-92,2)$ & $\begin{array}{l}121,9 \\
(30,2-156,3) \\
133,9 \\
(36,5-179,6)\end{array}$ & $\begin{array}{l}102,4) \\
58,8 \\
(16,6- \\
101,6)\end{array}$ & $(69,6-146,1)$ \\
\hline
\end{tabular}

n (tamanho amostral) 15: número de meses amostrados em cada profundidade.

Tabela 3 - Comparação entre as médias, mínimos e máximos (nos parênteses) do nitrogênio amoniacal (amônio) na coluna da água e na água intersticial da coluna sedimentar no Saco do Justino e no Saco da Mangueira (abril/94 a setembro/95).

\section{AMÔNIO ( $\left.\mu \mathrm{M} \mathrm{N}-\mathrm{NH}_{4}{ }^{+}\right)$}

\begin{tabular}{|c|c|c|c|c|}
\hline Profundidade & $\begin{array}{l}\text { Saco do } \\
\text { Justino } \\
\text { (área sem } \\
\text { efluentes) } \\
\text { Local 4 }\end{array}$ & $\begin{array}{l}\text { Saco da } \\
\text { Manqueira } \\
\text { (efluentes } \\
\text { industriais)l } \\
\text { Local } 3\end{array}$ & $\begin{array}{l}\text { (aportes de } \\
\text { água doce) } \\
\text { Local } \mathbf{2}\end{array}$ & $\begin{array}{l}\text { (efluentes } \\
\text { domésticos) } \\
\text { Local } 1\end{array}$ \\
\hline $\begin{array}{l}\text { Coluna d'água: } \\
\text { Superfície } \\
\text { Fundo }\end{array}$ & $\begin{array}{l}8,9 \\
(1,9-29,7) \\
14,2 \\
(4,1-29,0)\end{array}$ & $\begin{array}{l}24,5 \\
(2,3-63,8) \\
27,3 \\
(2,6-62,9)\end{array}$ & $\begin{array}{l}16,6 \\
(0-48,4) \\
13,2 \\
(3,5-40,2)\end{array}$ & $\begin{array}{l}28,6 \\
(1,7-47,9) \\
35,8 \\
(6,5-51,0)\end{array}$ \\
\hline
\end{tabular}


BAUMGARTEN; NIENCHESKI. A coluna sedimentar como reservatório e fonte de nutrientes em enseadas estuarinas.

\begin{tabular}{|c|c|c|c|c|}
\hline $\begin{array}{l}0,5 \mathrm{~cm} \\
\text { (interface) }\end{array}$ & $\begin{array}{l}97,0 \\
(40,7-216,7) \\
75,5\end{array}$ & & $\begin{array}{l}184,3 \\
(33,6- \\
710,7)\end{array}$ & $\begin{array}{l}228,6 \\
(51,2- \\
352,7)\end{array}$ \\
\hline 1 & $(20,3-132,6)$ & & 147,5 & 208,7 \\
\hline 2 & $\begin{array}{l}81,6 \\
(21,5-161,3)\end{array}$ & & $\begin{array}{l}(29,0- \\
316,0)\end{array}$ & $\begin{array}{l}(11,5- \\
576,6) \\
1903\end{array}$ \\
\hline 5 & $\begin{array}{l}115,84 \\
(31,7-348,0) \\
104,1\end{array}$ & & $\begin{array}{l}126,5) \\
(26,4- \\
451,4)\end{array}$ & $\begin{array}{l}190,3 \\
(58,0- \\
332,9)\end{array}$ \\
\hline 8 & $\begin{array}{l}(26,5-228,5) \\
203,5\end{array}$ & 166,9 & $\begin{array}{l}148,2 \\
(36,9-\end{array}$ & $\begin{array}{l}166,3 \\
(50,7-\end{array}$ \\
\hline 13 & $\begin{array}{l}(10,7-664,9) \\
307,5\end{array}$ & $\begin{array}{l}(61,9-596,7) \\
150,3\end{array}$ & $\begin{array}{l}302,7) \\
200,1\end{array}$ & $\begin{array}{l}445,0) \\
226,2\end{array}$ \\
\hline 18 & $\begin{array}{l}(16,6-947,9) \\
378,1\end{array}$ & $\begin{array}{l}(21,8-572,6) \\
172,8\end{array}$ & $\begin{array}{l}(39,8- \\
470,4)\end{array}$ & $\begin{array}{l}(61,9- \\
801,6)\end{array}$ \\
\hline 23 & $\begin{array}{l}(45,3- \\
1050,6)\end{array}$ & $\begin{array}{l}(43,9-316,8) \\
255,1\end{array}$ & $\begin{array}{l}392,5 \\
(44,4-\end{array}$ & $\begin{array}{l}264,6 \\
(63,7-\end{array}$ \\
\hline 28 & $\begin{array}{l}484,2 \\
(67,8-976,0)\end{array}$ & $\begin{array}{l}(45,0-523,0) \\
308,9\end{array}$ & $\begin{array}{l}1265,5) \\
437,1\end{array}$ & $\begin{array}{l}951,6) \\
398,6\end{array}$ \\
\hline 33 & $\begin{array}{l}462,3 \\
(67,8-976,0)\end{array}$ & $\begin{array}{l}(97,2-683,8) \\
403,7\end{array}$ & $\begin{array}{l}(39,2- \\
752,9)\end{array}$ & $\begin{array}{l}(110,2- \\
921,5)\end{array}$ \\
\hline 38 & $\begin{array}{l}566,4 \\
(80,8- \\
2106,8)\end{array}$ & $\begin{array}{l}(168,7-846,0) \\
487,2 \\
(268,4-913,5) \\
484,0 \\
(152,5-830,4) \\
484,2 \\
(131,4-769,7) \\
510,5 \\
(218,7- \\
1012,4) \\
518,3 \\
(262,8-899,3)\end{array}$ & $\begin{array}{l}581,9 \\
(153,9- \\
1050,5) \\
793,6 \\
(292,3- \\
1397,9) \\
828,5 \\
(173,6- \\
1859,9) \\
958,1 \\
(394,8- \\
1859,9)\end{array}$ & $\begin{array}{l}558,5 \\
(330,8- \\
892,8) \\
644,8 \\
(269,0- \\
949,9) \\
801,3 \\
(503,8- \\
971,5) \\
900,5 \\
(546,6- \\
1232,5)\end{array}$ \\
\hline
\end{tabular}

n (tamanho amostral) 15: número de meses amostrados em cada profundidade.

\section{DISCUSSÃo}

As intensas variações espaço-temporais na coluna d'água e na água intersticial das concentrações dos nutrientes não apresentaram nitidamente uma variação sazonal. Foram conseqüência dos diferentes nível, tipo e freqüência de aportes antrópicos em cada local amostrado, além de serem nitidamente influenciadas pela entrada e permanência da água marinha no estuário e, simultâneamente nas enseadas (março a julho de 1995). A penetração da água marinha foi proporcionada pela ocorrência de ventos do quadrante sul na região, empurrando a água costeira para dentro de toda a parte sul do estuário. Isso fez com que as enseadas não se diferenciassem em termos da salinidade.

A constatação da variabilidade temporal da composição de amônio da água intersticial da superfície e sub-superfície da coluna sedimentar da plataforma continental já foi enfatizada por JAHNKE et al. (2005). Justificaram que as variações nas concentrações deste nutriente foram influenciadas pelas mudanças na temperatura ambiental e nas diferenças de aportes de carbono orgânico para a coluna sedimentar ao longo do ano. Portanto, as conclusões destes autores comparadas com os resultados do presente estudo, evidenciam que em enseadas rasas estuarinas, além da temperatura e do aporte de matéria orgânica, a penetração da água marinha na coluna sedimentar tem um papel de destaque na contribuição de nutrientes para a coluna d'água..

Em função dos aspectos acima apresentados, no presente estudo os resultados dos nutrientes foram interpretados separadamente considerando três condições salinas 
distintas nas enseadas: antes da entrada da água marinha, durante e depois, as quais ocorreram ao longo do período amostrado e são freqüentes no estuário da Lagoa dos Patos, embora sem ciclo sazonal definido.

\section{Período precedente à entrada da água marinha no estuário (abril de 1994 a janeiro de 1995)}

\section{Coluna d'água}

Nas oito amostragens realizadas nesse período predominou o regime de vazante e raras vezes ocorreu uma fraca enchente no estuário, com a presença de águas mixohalinas de baixa salinidade em ambas enseadas (menores que 15 na coluna d'água e 10 na água intersticial). Essa é a condição salina mais comum e freqüênte nas águas das enseadas estudadas, favorecida pela predominância ao longo do ano de ventos de direções norte/nordeste..

Em termos de nutrientes, nessa ocasião o Saco do Justino (local 4) se destacou pelas muito baixas concentrações de fosfato da coluna d'água, devido à ausência de fontes antrópicas. Essas concentrações foram levemente mais elevadas no fundo e variaram pouco e em torno de $1 \mu \mathrm{M}$ (Fig. 2), que é o valor citado como normal para ambientes costeiros não contaminados (AMINOT \& CHAUSSEPIED, 1983). No Saco da Mangueira, as concentrações de fosfato foram mais elevadas, principalmente no local 1 , devido aos intensos aportes dos efluentes domésticos nesse local.

Os acréscimos de fosfato no local 3 indicaram a nítida influência dos rejeitos aéreos e hídricos oriundos das indústrias de fertilizantes presentes nas proximidades desse local. As emissões das indústrias de fertilizantes podem conter fósforo, devido a perdas no processo industrial, seja a partir da rocha fosfatada (matéria prima para a produção de fertilizantes), cuja composição tem até $39 \%$ de $\mathrm{P}_{2} \mathrm{O}_{5}$, ou de outras atividades dessa indústria (SORIA \& CHAVARRIA, 1978). As poeiras fosfatadas podem ser emitidas pelas chaminés e se depositarem nos sedimentos adjacentes à indústria. A partir disso, estes compostos podem se hidrolizar e redissolver, gerando mais fosfato dissolvido. Estas indústrias também têm efluentes líquidos que, embora oficialmente sejam considerados somente pluviais, por eles escorrem as águas da chuva que lavam a planta industrial, enriquecendo-se nos elementos químicos constituintes das emissões aéreas depositadas sobre toda a instalação da indústria. Visualmente, foram percebidos intensos depósitos dessas poeiras nas valetas por onde esses efluentes hídricos deságuam no Saco da Mangueira.

Em termos de amônio na coluna d'água, nesse período o padrão foi diferente do fosfato, pois ocorreram altas concentrações em todos os locais, inclusive no Saco do Justino (Fig. 2), embora aí os picos foram menos pronunciados, mas evidenciaram concentrações máximas em torno de seis vezes mais elevadas que o valor de $5 \mu \mathrm{M}$, citado como normal para ambientes costeiros (DAY et al., 1987) (Tabela 2). Portanto, em regime de vazante nas enseadas, a água se apresenta mais enriquecida em amônio.

No Saco da Mangueira as concentrações de amônio foram maiores, pois atingiram valores em torno de dez vezes mais elevadas que o valor acima citado como normal. 0 período de ocorrência desses picos não foi coincidente entre os locais, o que identificou diferentes fontes antrópicas atuantes em cada local e que se somaram ao aporte via coluna sedimentar ocorrente em todos os locais.

Particularmente no local 1 , a constante contaminação da água em amônio nesse período foi conseqüência dos lançamentos dos vários efluentes domésticos clandestinos presentes nessa margem do Saco da Mangueira, somados aos efluentes de duas indústrias de processamento de pescados situadas nas proximidades. Todos esses efluentes insuficientemente tratados são lançados visivelmente ricos em compostos protêicos (restos de fezes, de comida e de pescados), que que se decompõem junto ao fundo, liberando amônio para a coluna d'água (processo da amonificação da matéria orgânica, ESTEVES, 1998). Além disso, os efluentes domésticos não tratados são diretamente ricos em compostos amoniacais, oriundos de produtos de limpeza. 
BAUMGARTEN; NIENCHESKI. A coluna sedimentar como reservatório e fonte de nutrientes em enseadas estuarinas.

No local 3, a contaminação em amônio foi conseqüência das emissões das indústrias de fertilizantes, que além de fósforo, também podem conter nitrogênio como resultado de rejeitos da fabricação de fertilizantes dos tipos mono e diamônio fosfato. Entretanto, muito do nitrogênio (talvez a maior parte) carreado por essas emissões, pode estar na forma tóxica de $\mathrm{NH}_{3}$, sendo emitido como gás ou adsorvido em micro partículas químicas - aerossóis (SORIA \& CHAVARRIA, 1978). Esse gás se dissolve facilmente quando entra em contato com a coluna d'água e é considerado no resultado analítico do nitrogênio amoniacal (amônio).

No local 2, os picos de amônio somente se acentuaram no início do verão (Fig. 2). Como esse local tem características de uma marisma e fica mais distante dos lançamentos de efluentes, esses acréscimos podem ter sido favorecidos pela formação da anoxia na camada sedimentar favorecida pela fraca hidrodinâmica do local (fica no fundo da enseada). Assim, o amônio formado pela decomposição dos detritos autóctonos, produzidos pela intensa vegetação submersa e marginal do local (SEELIGER et al., 1998), enriqueceu a coluna d'água. Em época de maior temperatura fica favorecida a decomposição destes detritos depositados na coluna sedimentar (JAHNKE et al., 2005).

Os acréscimos de amônio no local 2 no início do verão distinguiram esse local dos outros estudados, onde simultaneamente ocorreu o contrário, ou seja, os picos de concentrações de amônio decresceram nesse período (Fig. 2). Esses decréscimos podem estar relacionados ao fato de que, estando os locais 1,3 e 4 posicionados em áreas mais abertas do que o local 2 (Fig. 1), neles é menor a retenção da matéria orgânica ou maior a oxigenação da água e da coluna sedimentar superficial, o que proporciona a maior diluição e dispersão do amônio formado ou a oxidação desse íon a nitrato (nitrificação). Além disso, no verão se desenvolveram nas enseadas florações, como de gramíneas submersas no Saco do Justino e de cianobactérias como a Aphanothece sp. (ARAÚJO, 2005) no Saco da Mangueira, além do microfitobentos, aumentando a fitoassimilação de nutrientes. As significativas elevações no $\mathrm{pH}$ e do oxigênio da água nesse período (chegou a 9,4 em janeiro/95, mantendo-a levemente alcalina desde novembro/94 até março/95) corrobora com essa hipótese, pois com o aumento nas taxas fotossintéticas, há consumo do gás carbônico que eleva o pH.e libera oxigênio dissolvido, favorecendo os processos oxidativos.

Com relação ao aumento da biomassa vegetal viva nesse período no estuário, SEELIGER et al. (1998) mostraram que em áreas rasas, a associação de baixa salinidade, alta temperatura e alta insolação da coluna d'água têm um efeito sinérgico sobre a germinação das sementes de Ruppia marítima, uma gramínea superior submersa que coloniza grande parte dos baixios deste estuário. A taxa de crescimento máximo desse vegetal começa no início da primavera e do verão e cessa no outono. ZARZUR (2001) sugeriu que o microfitobentos mais abundante no verão no Saco do Justino influenciou de forma direta e intensa os fluxos de liberação e o alto consumo de nutrientes na interface água/sedimento.

\section{Coluna sedimentar}

Comparando a coluna d'água com a água intersticial de ambas enseadas nesse período, constatou- que para a salinidade, o gradiente não se pronunciou entre a coluna d'água e a água intersticial da interface, evidenciando a mistura entre esses compartimentos nesssa ocasião. Entretanto, para os nutrientes os gradientes foram crescentes em direção ao fundo da coluna sedimentar (Fig. 3), sendo esses menos intensos para o fosfato do que para o amônio (Tabelas 1, 2 e 3). Em ambas enseadas, a água intersticial da interface apresentou concentrações de amônio numa média em torno de 10 vezes maior do que na coluna d'água. Para o fosfato esse fator, em média, foi de apenas cerca de 2 vezes,, mas foi crescente em direção ao fundo da coluna sedimentar..

$\mathrm{Na}$ coluna sedimentar a partir dos $10 \mathrm{~cm}$ de profundidade, entre agosto e novembro/94, se formaram acúmulos (núcleos) de água intersticial altamente enriquecida em amônio e em fosfato (Fig. 3), sendo esses mais intensos nos locais contaminados do Saco da Mangueira, ou seja, no local 1 se destacaram núcleos de 
amônio e local 3, de fosfato, o que seguiu o mesmo padrão observado na coluna d'água (Tabelas 3 e 4). A formação desses acúmulos foi favorecida porque nessa profundidade os sedimentos das enseadas estudadas se tornam mais compactados e estagnados, pois são mais finos que os mais superficiais. Na sub-superfície da coluna sedimentar da margem das enseadas estudadas, o percentual de finos oscila entre 40 a $70 \%$, enquanto que nas camadas mais superficiais, a predominância é para sedimentos de maior granulometria (<30\% de finos) (BAUMGARTEN et al., 2001). Além do mais, são os sedimentos das camadas mais superficiais que sofrem ressuspensão pelo aumento da intensidade de ventos na área das enseadas, quando há turbulência da coluna d'água muito rasa.

Portanto, a formação desses núcleos de concentrações também foi favorecida porque a hidrodinâmica ocorrente em ambas enseadas nesse período prévio da entrada da água marinha não foi suficiente para revolver a coluna sedimentar sub-superficial, o que dificultou a sua oxigenação e aumentou a compactação, criando condições muito redutoras localizadas (Eh negativo). Por isso, entre agosto e outubro/94, criou-se o forte gradiente de concentrações de nutrientes, com uma acentuada estratificação ao longo da coluna sedimentar, formando-se uma barreira constituída por camadas oxidantes desde a superfície até a profundidade de cerca de $15 \mathrm{~cm}$, a partir do que, o Eh apresentou-se muito redutor (chegou a ser cerca de $-360 \mathrm{mv}$ entre 33 a $38 \mathrm{~cm}$ de profundidade).

Estes gradientes se salientaram nos locais 1 e 3, onde há muitas fontes antrópicas de matéria orgânica e poeiras ou partículas fosfatadas, que se soterram e se decompõem ou se dissolvem na coluna sedimentar, enriquecendo proporcionalmente a água intersticial, principalmente das camadas de sedimentos mais finos, mais profundas.

Particularmente com relação ao fosfato, segundo BREPHOL (2000), a condição redutora favorece a sua manutenção na forma dissolvida, principalmente quando esse íon está associado com formas reduzidas do ferro e do manganês, formando sais solúveis. Portanto, o fluxo de fosfato via água intersticial para a coluna d'água e a busca do equilíbrio de concentrações entre esses compartimentos ambientais é fortemente controlado pelo prevalecimento da condição redutora na coluna sedimentar. A presença de uma camada oxidante na coluna sedimentar superficial pode impedir ou dificultar o fluxo de fosfato para a coluna d'água. Essa camada funciona como uma armadilha para manter o fosfato retido na coluna sedimentar mais profunda (mais de $15 \mathrm{~cm}$ ), o que ficou evidente na Figura 3.

Assim, o fosfato difundido das camadas mais profundas para as mais superficiais da coluna sedimentar, quando encontrou essa barreira oxidante superficial, pode ter sido aprisionado nos sedimentos da mesma (adsorvido), principalmente em colóides como óxidos ou hidróxidos hidratados de ferro ou de manganês (ESTEVES, 1998, TENGBERG et al., 2003). Esse processo é conhecido como uma armadilha do fosfato pela coluna sedimentar, citado para ambientes de baixa hidrodinâmica (LISS et al., 1976). Nessa situação diminuíram as concentrações de fosfato dissolvido na água intersticial das camadas superficiais da coluna sedimentar, havendo menor contribuição para a coluna d'água, porque se estabeleceu um relativo equilíbrio iônico entre a coluna d'água e a coluna sedimentar superficial.

Portanto, os resultados comprovaram que quando a coluna sedimentar é pouco perturbada naturalmente (fraca hidrodinâmica) ou artificialmente (ambiente não dragado, submetido a redes de arrasto ou pisoteado, por exemplo), o alto enriquecimento de fosfato na coluna d'água, como foi constatado no local 3 , tem a principal origem nas emissões antrópicas, como as das indústrias de fertilizantes, já que a coluna sedimentar embora contaminada, contribui de forma limitada devido a barreira oxidante superficial que se forma na coluna sedimentar nessa situação ambiental.

Com relação ao amônio, as altas concentrações acumuladas na coluna sedimentar, principalmente no local 1 e, seguido do local 3, mais contaminados do Saco da Mangueira, foram motivadas pelo soterramento e decomposição de matéria orgânica detrítica e redissolução de compostos nitrogenados, o que enriquece em amônio a água 
BAUMGARTEN; NIENCHESKI. A coluna sedimentar como reservatório e fonte de nutrientes em enseadas estuarinas.

intersticial.. A condição redutora desfavorece a sua oxidação a nitrato, mantendo-o na forma original formada pela decomposição da matéria orgânica. Isso implicou na formação do intenso e abrupto gradiente crescente de concentração de amônio a partir da interface da coluna sedimentar (mais oxidante), resultando numa maior contribuição de amônio para a coluna d'água, por difusão iônica a partir da coluna sedimentar, em comparação com o fosfato, embora para qual também tenha havido contribuição da coluna sedimentar por difusão iônica.Isso resultou no favorecimento da visível eutrofização dos locais 1 e 3 no Saco da Mangueira nessa época.

Particularmente com relação aos gradientes de amônio entre a coluna d'água e a coluna sedimentar, JAHNKE et al (2005) estudando a água intersticial de sedimentos muito permeáveis na plataforma continental do Atlântico Sul até cerca de $16 \mathrm{~cm}$ de profundidade, não salientaram gradientes crescentes para o amônio. Portanto, o gradiente registrado por esses autores foi no sentido contrário daquele constatado no presente estudo no estuário da Lagoa dos Patos. Esses autores acima citados justificaram as maiores concentrações nas camadas mais superficiais em função da maior mineralização da matéria orgânica depositada, não caracterizando o gradiente crescente na direção das maiores profundidades da coluna sedimentar.

Portanto, as variações da granulometria diferenciada ao longo da coluna sedimentar, da ressuspensão de sedimentos superficiais e da relativa fraca hidrodinâmica ocorrentes nas enseadas do estuário da Lagoa dos Patos, justificam os gradientes encontrados aqui.

\section{Período da entrada e dominância da água marinha no estuário (março a julho de 1995)}

\section{Coluna d'água e interface com a coluna sedimentar}

O aumento importante da salinidade a partir de março até julho/95 (outono/inverno, Figuras 2 e 3), quando dominaram águas fortemente mixohalinas em ambas enseadas e a salinidade evoluiu até 20 no Saco do Justino e 25 no Saco da Mangueira, foi conseqüência da ocorrência de fortes ventos vindos dos quadrantes sul e oeste. Estes empurraram a água costeira para dentro do estuário, fazendo-a chegar até o Saco do Justino. Portanto, as variações da salinidade não obedeceram rigorosamente um padrão sazonal, evidenciando uma instabilidade salina da região. Apresentaram um comportamento diferenciado daquele mais freqüente no estuário, onde normalmente é no verão que a salinidade aumenta e a água marinha entra, em função da baixa no índice pluviométrico e do nível do estário (BAUMGARTEN et al., 1995; MOLLER et al., 1991).

Nessa época em termos de amônio na coluna d'água novamente se destacaram os locais 1 e 3 como os mais contaminados do Saco da Mangueira, onde ocorreram importantes acréscimos de concentrações (em junho/95, Fig. 2), cuja magnitude dependeu do enriquecimento da coluna sedimentar em amônio e fosfato no período anterior à entrada da água marinha. Portanto, a penetração dessa água ressuspendeu os sedimentos superficiais e sub-superficiais, perturbando a relativa estagnação anterior da coluna sedimentar. Assim, foi liberado para a coluna d'água a água intersticial enriquecida com o amônio, se dispersando os núcleos de concentrações formados antes da entrada da água marinha.

Com relação ao fosfato na coluna d'água dos locais 1, 2 no Saco da Mangueira e no local 4 no Saco do Justino, houve diluição das concentrações devido a penetração da água marinha (Fig. 2).. Entretanto, isso não ocorreu no local 3 para o fosfato, onde os aportes deste nutriente via emissões industriais foram mais significativos que a diluição, aumentando a contaminação na água. A sobrecarga de fosfato na coluna d'água do local 3 desencadeou a eutrofização primaveril desse local, com visíveis florações da cianobactéria Aphanothece sp., nas margens, a qual é muito conhecida na região como Ranho de Marinheiro (ARAÚJO, 2005). 


\section{Coluna sedimentar}

A penetração da água marinha na coluna sedimentar manteve a salinidade da água intersticial de até cerca de 10 a $15 \mathrm{~cm}$ de profundidade muito semelhante aquela da coluna d'água, evidenciando um intercâmbio e um equilíbrio salino entre esses compartimentos ambientais durante a dominância da água marinha nas enseadas, de forma semelhante ao constatado na condição salina anteriormente descrita. Esse equilíbrio iônico entre coluna d'água e a coluna sedimentar superficial foi favorecido pela maior densidade da água marinha e maior salinidade em relação à água intersticial, facilitando a difusão iônica entre líquidos de diferentes concentrações e aumentando a salinidade da água intersticial da interface.

A Figura 3, (no gráfico que se refere a salinidade) ilustra esse processo salino no Saco do Justino, igual ao constatado no Saco da Mangueira. Em função disso, nas camadas mais profundas da coluna sedimentar ocorreram águas fracamente mixohalinas enquanto a água marinha dominou a coluna d'água e a interface. Isso proporcionou um gradiente decrescente para a salinidade, a partir da coluna d'água, ou seja, um gradiente de salinidade com sentido oposto àquele constatado quando a coluna d'água apresentou fraca salinidade (período anterior à entrada da água salina).

Essa inversão do sentido do gradiente salino é resultado de que nas maiores profundidades da coluna sedimentar a água é sempre mixohalina (pelo menos até 50 $\mathrm{cm}$ ), em maior ou menor intensidade, conseqüência de que aí há maior estabilidade salina e maior integração temporal das variações que ocorreram na coluna d'água.

Em termos de nutrientes, com a penetração da água marinha houve desestabilização da estratificação da coluna sedimentar sub-superficial, começando o gradativo desaparecimento por dispersão dos núcleos de amônio formados antes desse período. Isso foi constatado mais intensamente para o amônio do que para o fosfato, pois parte do amônio pode também ter se oxidado a nitrato (nitrificação) nessa ocasião, em função da maior oxigenação causada na coluna sedimentar devido à presença da água marinha bem aerada. O fato de que nessa época ficaram positivos os resultados de Eh até $25 \mathrm{~cm}$ de profundidade da coluna sedimentar (condição oxidante) corrobora com a hipótese acima apresentada.

Com relação aos gradientes de concentrações, para os nutrientes o padrão de variação temporal foi diferente daquele da salinidade e se manteve sempre crescente, da mesma maneira como no período anterior à penetração da água marinha. A diferença é que agora, após a dispersão e a diluição dos núcleos de concentrações de nutrientes pela água marinha, a amplitude das concentrações dos gradientes foi bem menor, sendo assim menos abruptos..

Para o fosfato, o gradiente novamente foi muito mais fraco do que para o amônio, porque as concentrações de fosfato da água intersticial dos primeiros $10 \mathrm{~cm}$ de profundidade se elevaram com a entrada da água marinha (Fig. 3), apesar da diluição causada pela mesma. O enriquecimento em fosfato na água intersticial da coluna sedimentar superficial e simultaneamente do fundo da coluna d'água, pode ter sido causado por dois processos que desfavorecem a adsorção do fosfato nas partículas, mantendo o fosfato dissolvido.

O primeiro processo se refere a que a penetração da água marinha na coluna sedimentar desestabilizou a estratificação da mesma, rompendo a barreira oxidante que havia se formado nas camadas superficiais e que favorecia a adsorção formada no período antes da entrada da água marinha e, então a formação de um gradiente mais abrupto. Isso favoreceu a migração por advecção para a interface e para a coluna d'água, da água intersticial contaminada em fosfato (além do amônio), que estava retida nos núcleos e a manutenção do fosfato dissolvido nas camadas mais superficiais (Fig. 3). Este processo ficou visível no gráfico de fosfato apresentado na figura 2.

Um segundo processo se refere a alta carga da água marinha em outros ânions diferentes do fosfato, como sulfatos, cloretos e hidroxilas ou agentes quelantes. Isso 
BAUMGARTEN; NIENCHESKI. A coluna sedimentar como reservatório e fonte de nutrientes em enseadas estuarinas.

causa bloqueio para os ânions (saturação) dos sítios de adsorção dos sedimentos da coluna sedimentar (JAHNKE et al., 2000), o que desfavorece a adsorção do fosfato dissolvido que migrou das camadas profundas da coluna sedimentar, apesar da interface apresentar condições oxidantes.

Portanto, o relativo equilíbrio nas concentrações de fosfato entre a coluna d'água e a coluna sedimentar superficial nessa ocasião (ambas enriquecidas), evidenciou um intenso intercâmbio e um processo de tamponamento de fosfato entre as concentrações desses compartimentos ambientais durante a penetração da água marinha na coluna sedimentar estuarina, processo esse já mencionado em 1976 por LISS et al..

Esse tipo de tamponamento das concentrações não ocorreu para o amônio, porque esse íon forma compostos predominantemente solúveis, independente da salinidade, e assim, não têm facilidade de adsorção em partículas (TENGBERG et al., 2003).. A remoção do amônio na interface é intensa por absorção pelo fitobentos ou é por nitrificação (ZARZUR, 2001), mantendo evidente o gradiente crescente nos locais estudados, com a água intersticial superficial muito mais concentrada (em torno de 10 vezes) que a coluna d'água adjacente. A magnitude das concentrações de amônio sempre esteve na dependência dos aportes de matéria orgânica antrópica que cada local recebe.

\section{Período posterior à entrada da água marinha (agosto e setembro de 1995) \\ Coluna da'água}

Passado o período de permanência da água marinha no estuário, cujo tempo depende da ocorrência de ventos do quadrante sul e fracas chuvas, a tendência dessa água é se diluir no estuário ou voltar novamente para a costa em função do restabelecimento de um novo regime de vazante. Por isso, a partir de agosto de 1995, em todos os locais a salinidade foi menor que 10, num padrão de vazante comum para 0 inverno nesse estuário.

Em termos de nutrientes, somente o local 4 no Saco do Justino e o local 2 no Saco da Mangueira, os menos contaminados, apresentaram intensos decréscimos nas concentrações na coluna d'água. Os locais 1 e 3, continuaram a apresentar a coluna d'água contaminada (Fig. 2), como conseqüência do permanente aporte de efluentes para os mesmos, independente da presença ou não da água marinha no estuário.

\section{Coluna sedimentar}

Houve decréscimos das concentrações de amônio e fosfato em todos os locais, embora nos locais 1 e 3 isso tenha ocorrido menos intensamente, como reflexo da contaminação da coluna d'água.

Apesar da hidrodinâmica estar reduzida em relação ao período anterior de entrada da água marinha, os núcleos de concentrações não voltaram a se formar imediatamente, pelo menos nos dois meses amostrados após a dominância da água marinha.Isso pode se caracterizar como uma conseqüência do processo acima discutido de "descontaminação" da coluna sedimenta.

Portanto, após a perturbação da coluna sedimentar pela penetração da água marinha, nos locais mais naturais (Saco do Justino e local 2) houve a manutenção do equilíbrio iônico entre a coluna d'água e a coluna sedimentar que ficou menos enriquecida em nutrientes, diminuindo a sua contribuição para a coluna d'água. Nos locais receptores de efluentes continuou a predominância dos sportes antrópicos em relação à contribuição da coluna sedimentar.

A manutenção ao longo do tempo desse abrandamento no gradiente das concentrações ao longo da coluna sedimentar após a penetração da água marinha é instável, e depende imensamente da hidrodinâmica que venha a ocorrer nas enseadas estudadas. Provavelmente, se a água marinha não penetrar novamente na coluna sedimentar num espaço de tempo maior que cerca de 2 meses (período estudado) após a sua última entrada, formar-se-ão novos acúmulos de fosfato e de amônio na coluna 
sedimentar durante os meses subseqüentes, favorecidos pela estagnação e nova estratificação no Eh das camadas sedimentares sub-superficiais (estagnadas) e pela barreira oxidante formada nas camadas mais superficiais. Por outro lado, se a água marinha penetrar novamente em curto espaço de tempo, a formação dos núcleos de altas concentrações na coluna sedimentar não será favorecida.

\section{CONCLUSÂO}

Os períodos de relativa fraca hidrodinâmica e de simultânea dominância de águas doces ou levemente mixohalinas nas enseadas do estuário da Lagoa dos Patos foram predominantes. Foi quando se acentuaram os gradientes crescentes de concentrações dos nutrientes desde a coluna d'água em direção ao fundo da coluna sedimentar (até cerca de $50 \mathrm{~cm}$ de profundidade). Houve a formação de acúmulos (núcleos) de água intersticial muito contaminada nas maiores profundidades, onde os sedimentos são mais finos e redutores. Nesta situação, houve maior difusão iônica para a coluna d'água, principalmente para o amônio. Para o fosfato, a camada oxidante que se formou na superfície da coluna sedimentar, favoreceu a remoção por adsorção da forma dissolvida desse fitonutriente que se difundia das camadas mais profundas, gerando uma "armadilha" para o ele na interface, o que diminuiu a sua dispersão para a coluna d'água.

Portanto, para o fosfato foi gerado um relativo equilíbrio iônico (tamponamento) entre a coluna d'água e a água intersticial até cerca de $10 \mathrm{~cm}$ de profundidade da coluna sedimentar. Isso resultou em que a amplitude de concentrações no gradiente de fosfato foi muito menor do que para o amônio. As concentrações de amônio na coluna d'água foram cerca de dez vezes menores que aquelas da água intersticial da interface, enquanto que para o fosfato foi duas vezes menores.

A entrada da água marinha e oligotrófica nas enseadas (regime de enchente) foi regulada pela complexa hidrodinâmica do estuário, não apresentando freqüência sazonal e ocorrendo na presença de ventos do quadrante sul. Nessa ocasião, o gradiente de salinidade foi decrescente desde a coluna d'água, contrário dos gradientes dos nutrientes e também daquele crescente registrado para a salinidade no período anterior, quando a coluna d'água estava dominada por água de baixa salinidade. Como a água intersticial de maiores profundidades da coluna sedimentar das enseadas possui um maior tempo de residência, integrou e amenizou as variações da salinidade mais intensamente do que a coluna d'água, permanecendo sempre com água intersticial mixohalina.

Quanto aos nutrientes, a penetração da água marinha na coluna sedimentar aumentou os intercâmbios dessa com a coluna d'água e ressuspendeu os sedimentos superficiais, perturbando a estabilidade da coluna sedimentar. Houve rompimento da estratificação formada entre as camadas oxidantes superficiais e as redutoras mais profundas. Assim, a água intersticial altamente contaminada em amônio e fosfato foi liberada e, num primeiro momento enriqueceu a interface e a coluna d'água. Esse processo se assemelha a uma perturbação artificial e momentâneo da coluna sedimentar, como uma dragagem, por exemplo. Num segundo momento, após a dominância da água marinha nas enseadas, os gradientes de concentração foram amenizados como conseqüência da diluição e descontaminação da coluna sedimentar durante a penetração da água marinha na mesma. Esse processo se manteve até novo restabelecimento do regime de vazante com diminuição da hidrodinâmica nas enseadas.

Portanto, a coluna sedimentar das enseadas funcionou como um reservatório de nutrientes, principalmente quando a sua estratificação foi favorecida pela fraca hidrodinâmica. Constitui-se na fonte natural e permanente de nutrientes para a coluna d'água ao longo do ano. Quanto mais contaminada ela for, maior será sua contribuição em nutrientes para a coluna d'água e maior a amplitude dos gradientes de concentrações entre esses compartimentos ambientais. No Saco do Justino, local "controle" em função de não receber aportes antrópicos, a coluna d'água se apresentou oligotrófica. Assim, a contribuição da coluna sedimentar no aporte de nutrientes foi imprescindível para a sua produtividade. Por isso, os vegetais fixados no substrato buscam o fosfato na água intersticial mais profunda, o que justifica a presença de muitas raízes finas penetrantes 
BAUMGARTEN; NIENCHESKI. A coluna sedimentar como reservatório e fonte de nutrientes em enseadas estuarinas.

até cerca de $15 \mathrm{~cm}$ da coluna sedimentar dessa enseada. Com isso, o fosfato da coluna d'água não representa um fator limitante à produção deste tipo de vegetais em enseadas naturais, embora seja limitante para o fitoplâncton.

Por outro lado, no Saco da Mangueira a contribuição em nutrientes pela coluna sedimenta ficou menosprezada nos locais onde há aportes diretos antrópicos de fitonutrientes para a coluna d'água.. Nessa enseada, a coluna d'água se apresentou cerca de duas vezes mais contaminada em amônio e fosfato do que no Saco do Justino, o que implicou na extrapolação da capacidade de equilíbrio trófico da mesma, proporcionando eutrofização muito evidente nas margens.

Por fim, os resultados evidenciaram que em ambas enseadas amostradas foram identificados os mesmos processos biogeoquímicos e de difusão/advecção atuantes na contribuição da coluna sedimentar para a composição da coluna d'água, independente do nível de contaminação de cada uma. A diferença entre elas foi que a intensidade da ocorrência desses processos é dependente dos diferentes tipos e intensidades das fontes antrópicas atuantes e da hidrodinâmica ocorrente, que é principal forçante que leva a água marinha a penetrar na coluna sedimentar e a perturbá-la com relativa posterior descontaminação. Em termos de amostragens nas enseadas do estuário, tanto na coluna d'água ou na coluna sedimentar, essas devem ser executadas, no mínimo na dominância de águas doces e de águas marinhas, pois a penetração dessa última na coluna sedimentar altera em curto espaço de tempo os processos e intercâmbios geoquímicos.

\section{AGRADECIMENTOS}

A oceanóloga Bianca A. Martins Parizotto e aos técnicos químicos José Vanderlen Veigas Miranda e Lúcia Helena Bohmer pelo valioso apoio e participações nas amostragens e nas análises.

\section{BIBLIOGRAFIA}

AMINOT, A \& CHAUSSEPIED, M. Manuel des analyses chimiques en milieu marin. CNEXO. Brest. 395 p. 1983.

ARAÚJO, E.A.C. Fatores ambientais que colaboram para a ocorrência de cianobactérias nas águas ao redor da cidade de Rio Grande (RS). Dissertação de Mestrado (Programa de Oceanografia Física, Química e Geológica). FURG, 112 p. 2005.

BAUMGARTEN, M.G.Z.; NIENCHESKI, L.F.H. \& KUROSHIMA, K.N. Qualidade das águas estearinas que margeiam o município de Rio Grande (RS - Brasil): nutrientes e detergente dissolvidos. Atlântica (17), p. 17-34. Editora da FURG. Rio Grande. 1995.

BAUMGARTEN, M.G.Z., ROCHA, J.M.B. \& NIENCHESKI, L.F.H. Manual de análises em Oceanografia Química. Editora da FURG. Rio Grande. 143 p. 1996

BAUMGARTEN, M.G.Z.; NIENCHESKI, L.F.H. \& VEECK, L.Nutrientes na coluna d'água e na água intersticial de sedimentos de uma enseada rasa estuarina com aportes de origem antrópica (RS - Brasil). Atlântica (23), p. 101-116. Editora da FURG. Rio Grande. 2001.

BREPHOL, D. Fósforo: intercâmbio entre a água e o sedimento de uma enseada rasa estuarina com aporte antrópico no estuário da Lagoa dos Patos (RS-Brasil). Dissertação (Mestrado em Oceanografia Física, Química e Geológica) -. FURG. P. 119. 2000.

CONSELHO NACIONAL DO MEIO AMBIENTE (CONAMA). Resolução n 357 de 17 de março de 2005. DOU n 53 de 30 de julho. Revoga da Resolução CONAMA n 20 de 1986. 2005.

DAY Jr., J.W., HALL, C.A.S., KEMP, W.M. \& YANEZ-ARANCIBIA, A. Estuarine chemistry. In: Estuarine Ecology. Cap. 3. Ed. Wiley. New York. p. 79-143. 1987.

ESTEVES, F.A. Fundamentos de Limnologia. $2^{a}$ ed. Ed. Interciência Ltda. Rio de Janeiro, 602 p. 1998.

FUNDAÇÃO ESTADUAL DE PROTEÇÃO AMBIENTAL (FEPAM). Portaria SSMA n 7 . Norma Técnica 003/95. Enquadramento dos recursos aquáticos da parte sul do estuário da Lagoa dos Patos. DOU, 24 de maio. 1995. 
JAHNKE, R.A.; NELSON, J.R.; MARINELLI, R.L. \& ECKMAN, J.E. Benthic flux of biogenic elements on the Southeastern US continental shelf: influence of pore water advective transport and benthic microalgae. Continental Shelf Research. 20 (1): 109-127. 2000.

JAHNKE, R.A.; RICHARDS, M.; NELSON, J.; ROBERTSON, C.; RAO, A \& JAHNKE, D. Organic matter remineralization and porewater exchange rates in permeable South Atlantic Bight continental shelf sediments. Continental Shelf Research, 25: 1433-1452. 2005.

KENNISH, J. Pratical handbook of marine science. London.: CRC Press. 576 p. 1994.

LISS, P.S Conservative and non conservative behaviour of dissolved constituents during estuarine mixing. In:. Estuarine chemistry. Cap. 4. Org. Burton, J.D. \& Liss, P.S. Acad. Press, London. p. 93-127. 1976.

MOLLER Jr., O.O.; PAIM, P.S.G \& SOARES, I.D. Factors et mecanismes de la circulation des eaux dans le estuaire de la Lagune dos Patos (RS, Bresil). Bull. Insr. Géol. Bassin d'Aquitaine. Bordeaux, n 49. p. 15-21. 1991.

NIENCHESKI, L.F.H \& JAHNKE, R.A. Benthic respiration and inorganic nutrient fluxes in the estuarine region of Patos Lagoon (Brazil). Aquatic Geochemistry. 8: (135-152).2002.

SEELIGER, U.; COSTA, C.S.B. \& ABREU, P.C. Fluxo de energia e habitats no estuário da Lagoa dos Patos. In: Os ecossistemas costeiros e marinhos do extremo sul do Brasil. Capítulo 5 (5.1). Eds.: U. Seeliger, C. Odebrecht \& Castello, J.P. Editora Ecoscientia. Rio Grande, 341 p. 1998.

SPENGLER, A.; WALLNER-KERSANACH,M. \& BAUMGARTEN, M.G>Z. Rio Grande municipal dump site impact in the estuary of Patos Lagoon (RS, Brazil). Acta Limnol. Bras., 19 (2):197-210. 2007.

SORIA, F.L. \& CHAVARRIA, J.M. Técnicas de defensa del medio ambiente. Vol. 2. Editorial Labor S/A. Calábria. p. 235-39. 1978.

TENGBERG, A.; ALMROTH, E \& HALL, P.O.J. Ressuspension and its effects on organic carbon recycling and nutrient exchange in coastal sediments: in situ measurements using new experimental technology. Journal of Experimental Marine Biology and Ecology: 119142. 2003.

ZARZUR, S. Fluxos e regeneração bêntica de nutrientes nas áreas rasas do estuário da Lagoa dos Patos. Dissertação de Mestrado (Programa de Oceanografia Física, Química e Geológica). FURG, 125 p. 2001.

ZARZUR, S. Regeneração bêntica de nutrientes e produção primária no estuário da Lagoa dos Patos Tese de Doutorado (Programa de Oceanografia Física, Química e Geológica). FURG, 218 p. 2007. 